MedieKultur | Journal of media and communication research | ISSN 1901-9726

Article - Theme section

\title{
I'd rather be a cyborg than a gamerbro How masculinity mediates research on digital play
}

\section{Nicholas Taylor}

MedieKultur 2018, 64, 10-30

Published by SMID | Society of Media researchers In Denmark | www.smid.dk

The online version of this text can be found open access at https://tidsskrift.dk/mediekultur

\begin{abstract}
This article offers a feminist and media-theoretical approach to ethnographic reflexivity, understood as the researcher's own agency in shaping encounters with and producing accounts of digital cultures. Looking specifically at male-dominated domains of intensive and competitive play in public sites, such as arcades, local area network (LAN) parties, and eSports tournaments, this article asks: How might masculinity mediate studies of digital play? To address this, I weave together feminist ethnography with materialist media theory, offering an understanding of researcher subjectivity (in this case, my subjectivity) as a media instrument: An assemblage of social locations and learned competencies which does not simply gather, but configures and legitimates, particular knowledges about gaming cultures. Applying this to a problematic instance from fieldwork I conducted at a large-scale gaming event in 2011, I work through the methodological and epistemological quandaries associated with both studying and embodying the social privileges associated with male-dominated media cultures.
\end{abstract}




\section{Introduction}

In recent years, we have seen intensifying associations between certain media industries, platforms, and practices, and regressive formations of masculinity, what some have coined toxic and/or hyper masculinity (see Banet-Weiser \& Miltner, 2016; Phillips, 2015). Certainly, questions of how gendered hierarchies are remediated via games, social media, film, and television are as important as ever. Another vital question, however, concerns the ways in which masculinity itself mediates studies of digital culture. In addressing this question, I follow the insights of feminist, queer, and decolonizing researchers who have highlighted the roles which researchers' positionalities play in shaping ethnographic knowledge (Davies, 1999; Lather, 1986; Visweswaran, 1994), and the adjacent insight from media anthropology (Abu-Lughod, 1997; Mankekar, 1999; Murphy, 2008) that all accounts of ethnographic encounters are themselves media texts, produced using historically and culturally situated techniques of recording, processing, and transmitting.

In this article, I offer one account of how the gendered positioning of researchers who study digital cultures mediates our exchanges with study participants-shaping what can be seen, said, heard, known, and shared about the very patterns of privilege and oppression which we both inhabit and observe. The specific subject under consideration here is me, and my own qualitative fieldwork; the specific domain I engage is intensive and competitive gaming, which remains heavily male-dominated (Harper, 2014; Ratan et al., 2015; Taylor, Jenson, \& de Castell, 2009), even as the broader landscape of digital play has seen some recent tendencies toward greater inclusivity, however precarious (Chess, 2017; Shaw, 2015).

In addition to the ethnographic traditions mentioned above, this work builds upon and extends scholarship in critical masculinity studies, which "arose from the feminist breakthrough that created women's studies and gender studies" and, as such, is epistemologically and politically aligned with feminist and queer scholarship (Connell, 2014, p. 6). Critical masculinity studies regard masculinities as enactments (and legitimators) of gender-based oppression. This approach to masculinities sits in opposition to "men's studies" (Messner, 2016) which mobilize essentialist notions of gender in order to valorize conventional (and deeply hierarchical) discourses of masculinity and which find renewed influence among the reactionary politics and ideologies of the online "manosphere" (Ging, 2017).

In recent years, online communities loosely associated with the alt-right have played a key role in the cultural and political ascendancy of toxic and regressive masculinity (Massanari, 2017), making feminist accounts of masculinized media practices both urgent and fraught. This is particularly noteworthy in the wake of the gamergate hate campaign, with its vitriolic attack on feminist modes of knowledge production (academic or otherwise), and the redeployment of media tactics associated with gamergate in the service of the USA's 2016 national election (Cross, 2017). 
At the same time, game scholars, along with their allies in game criticism and cultural production, have become favorite targets of the ever-aggrieved manosphere and its seemingly limitless belligerence (Chess \& Shaw, 2015), and feminist knowledge production has itself become an intensive site of struggle over the cultural meanings of games. When feminist game scholars can be stalked, harassed, or otherwise publicly and/or intrusively derided as social justice warriors, it is clear that game research is itself a site of contestation regarding who can participate, and how, in gaming cultures. Under these conditions, rigorous investigations of the gendered politics of knowledge production in game studies are crucial to our ongoing efforts to document, and possibly disrupt, the intersections of media and contemporary masculinity.

Yet, while a number of digital game scholars have offered invaluable insights into how they wrestle with their status as outsiders to the cultures they study in terms of gender, age, sexuality, race, and the multiple intersections of these systems of differentiation (Gray, 2012; Sundén, 2009; Taylor, 2012), there is little of the same reflexivity from maleidentified game researchers (see Johnson, 2010, for a valuable exception). This pattern seems to hold more broadly for media studies. There are numerous critical considerations of interactions between female scholars and study participants (see, for example, Mayer, 2001; Thomas, 1995), often involving considerations of class (Seiter, 1990), race (Mayer, 2006), and ethnicity (Pertierra \& Turner, 2013), but relatively few similar examinations are undertaken by male researchers. For game studies, such considerations on the part of researchers most able to pass as members of gaming's historically preferred demographic might yield much about how privileged social positions afford access to particular game-based interactions, relations, and, ultimately, knowledges. This line of inquiry might also shed light on how male-identified game researchers may, wittingly or not, help re-entrench any of the multiple forms of social exclusion associated with games, by participating unreflexively in exclusionary legacies of game-related cultural production (including scholarship).

What follows is a consideration of my fieldwork on male-dominated communities and events, including eSports tournaments, local area network (LAN) events, Internet cafés, and fan conventions, in which I ask what kinds of work the intersectional subjectivities of male-identified game researchers might do in producing accounts of conventionally masculinized gaming communities-and how might feminist traditions of social science both challenge and contribute to this work.

\section{Researching while straight, white, and male}

Intensive, and particularly competitive, gameplay forms a compelling site of research for game and new media scholars. Practices associated with intensive and competitive gameplay are at the forefront of major transformations in the casualization of work and the professionalization of gaming, and are sites for the experimentation in increasingly sophis- 
ticated techniques of attentional management and surveillance. Furthermore, as a robust body of work makes clear (Harper, 2014; Voorhees, 2015; Witkowski, 2013), these forms of play are crucial in understanding the shifting gendered politics of digital gaming more broadly, especially considering how eSports and its attendant economies gained traction in North America around the same time that Wii, smartphones, and other platforms and devices, as well as breakthrough titles such as The Sims, began to expand games beyond their typical core demographic of young, straight, and usually white males (Taylor, Jenson, $\&$ de Castell, 2009).

The gaming communities I have been drawn to in my research are overwhelmingly male-dominated, constituted by players whose identities (if not economic and/or vocational opportunities) are firmly rooted in their investments in elite-level, sustained play, and by discourses which traffic in a set of naturalized associations between gaming and the male body. Bodies are at the nexus of the gendered politics of intensive and especially competitive gameplay; as others have pointed out (Witkowski, 2013), players' bodies are at once the instruments and sites of these transformations. Changes in affect, attention, and perception heralded by competitive gaming are, perhaps most elementally, changes to bodies, and to our bodies' relationships with and within non-human assemblages (Giddings \& Kennedy, 2008).

However, the capacity to make sense of intensive play as an embodied practice must also, of necessity, involve a reflexive awareness of our own bodies and our own agencies as researchers. In other work (Taylor, 2016), I have considered this reflexivity in an attempt to understand how a video camera used for ethnographic documentation acts as both recording device and as a legitimating agent for a community of competitive gamers heavily invested in being watched. That work unpacked the implications of seeing our research instruments as agential in studies of play: as actors with their own histories, epistemologies, politics, and mobilities. Here, I explore reflexivity for a related, but distinct end: to better unpack the relations, modes of access, and forms of knowledge production which the researcher's body - my body-makes im/possible, and un/safe.

Primarily, I am interested in pointing to some of the pitfalls which I have encountered in my research in male-dominated communities of intensive play. These pitfalls have less to do with concerns around gender management in my interactions with participants, important considerations which have been addressed in studies of masculine contexts and communities (Ortiz, 2005). I am more interested in exploring how my own non-trivial investments in games and masculinity (persistent despite years of attempting to unlearn them) shape how I read, write, and make sense of these play contexts.

In taking up this exploration, I offer two provisional contributions-one theoretical and one methodological - to answering the question: "What can game research and media studies teach us about doing research on dynamic mediated interactions, sociotechnical relationships, and communication in spaces of play?" Theoretically, this paper builds on materialist theories of media. As articulated by Peters (2016), this scholarship 
takes an expansive (though not necessarily promiscuous) view as to what constitutes media, understanding them as techniques for bringing things together-an approach that acknowledges the mediating work undertaken not just by technological devices, but also by currencies, waterways, our bodies, and so on. Other characteristics of this approach include an attention to the material conditions of communication (Packer \& Wiley, 2012), as well as a concern with the infrastructures which enable mediation, rather than the content of any one set of messages. In this vein, and as its methodological contribution, this paper is concerned with exploring what, beyond the more obvious digital devices and platforms, might be mediating my ethnographic interactions with gamers. That is, what other less visible, but by no means incorporeal, infrastructures constitute the conditions of possibility for studying men who play games intensively? The pithy answer is masculinity.

\section{Masculinity as media apparatus}

In recent work (with Gerald Voorhees, forthcoming), I have sketched out a theorization of masculinity which is useful here. Building on Packer's articulation of the "media apparatus" as a way to account for media's increasingly central and unavoidable role in contemporary governance, I view contemporary hegemonic masculinity itself as a media apparatus. Packer defines a media apparatus as a network of "signs, signifiers, and technologies of inscription, collection, and processing," the purpose of which is the formation of subjects (Packer, 2013, p. 21). Understanding contemporary hegemonic masculinity as a media apparatus acknowledges the fundamental role of media technologies in producing masculine subjects. It entails looking at texts (games, films, and advertisements), contexts (man caves, sports bars, and offices), technologies (cars, game systems, and hygiene products), policies (family leave, crunch time, etc.) and other factors, as various elements of a mediated "machine of governance" (Packer, 2013, p. 20) which produces subjects invested in hegemonic masculinity.

As Packer states, however, digital media do not simply constitute processes of subjectivization; they also enable extensive objectification. Contemporary media apparatuses involve extensive techniques for generating information about media users, information which can be further deployed toward the project of governance. This might include, as examples, anything from the national census to video gameplay testing-techniques for generating data about users which are then used for demographic analyses, market research, micro-targeting, and other instruments of categorization, prediction, and control (Andrejevic, 2016; Packer, 2013, p. 19).

Games excel at such techniques; consider the highly sophisticated analytics at work in League of Legends, described by one writer as "the largest virtual psychology lab in the world" (Hsu, 2015). Along with this, we might include the quantified statistics of players' investment and skill, such as Elo ratings, achievements, gamerscores, character builds, and 
so on. Paul's (2018) articulation of how these metrics are deployed toward a "toxic meritocracy," characterizing many contemporary gaming cultures, offers a timely critique of these techniques. Certain strands of social scientific research on gaming play a key role as well, helping to naturalize differences in male vs. female play preferences, and in directly supporting game developers' efforts to maximize the amount of time, energy, and capital which players invest (see, for instance, Harrison \& Roberts, 2011).

Within the media apparatus of contemporary hegemonic masculinity, such techniques constitute what Packer calls "media instruments": the means for not simply recording and transmitting information, but for constituting the technological foundations on which we establish truths about players' abilities. Seen from this perspective, these aforementioned techniques help to produce information by, for, and about players, serving as one key production site in the construction of a "technomasculine" subjectivity which is ascendant in contemporary hegemonic masculinity (Johnson, forthcoming; Kocurek, 2015). This is a subject for whom technological competency is a pathway to cultural and economic ascendancy, is well-versed in the technical discourses of stats, strats and specs, whether applied to watching sports, playing games, buying toys, or hooking up.

Digital game researchers have demonstrated the costs (in harassment and marginalization) and limits (in terms of full cultural acceptance and potential professional and personal opportunities) which confront those who try to embody this subject position from conventionally marginalized genders and sexualities (Harper, 2014; Taylor, 2012; Taylor, Jenson, \& de Castell, 2009). Borrowing from pop culture, I refer to this technomasculine subjectivity in relation to games as the gamerbro. However, I do so by emphasizing that it is a construct, and one that is most readily embodied (though not exclusively) by cis-gendered, male-identified, straight, and usually white players.

This notion of masculinity as media apparatus, and the attention it gives to both the subjectifying and objectifying capacities of digital media, provides a useful framework through which I approach the claim that masculinity mediates encounters with maledominated contexts and communities. It follows, then, that researchers pay closer attention to the techniques of subjectification and objectification-the media instruments which produce power/knowledge - that we ourselves bring to bear on our research with digital cultures.

\section{Body as media instrument}

To further problematize the act of researching gamers while being straight, white, and male, I want to consider ethnographers' bodies themselves from this media-theoretical perspective, understanding them as media instruments. As Pink (2009) asserts, our sensory apparatus, our embodied identities, and our previous experiences with/in particular social worlds all contribute to our capacity to perceive and learn from the contexts we study. Weaving a theorization of media instruments together with the insights of sensory 
ethnography, I understand my body as a contingent and situated assemblage of privileged social location, methodological training, and affective attunements-one which does not simply gather, but makes (im)possible and (un)knowable particular insights about gamers and gaming.

So what kind of media instrument am I? I have attended nearly 100 physical sites of intensive play over the past decade as researcher, including LAN events, gaming nights, eSports tournaments and training sessions, gaming culture conventions, and so on. My body expects and is attuned to certain sensations, from the human-machine smell of close-quarters gaming (Behrenshausen, 2007; Niedenthal, 2012) to the soundscapes produced at different times of the day (and night). My work is hybrid (Burrell, 2009; Hine, 2015): I walk the floor, look over people's shoulders (and occasionally tap them), strike up conversations, and drink and eat with participants. I also record their gameplay, take screenshots, sometimes solicit surveys and/or online travelogues, and occasionally play with them.

Consistently, across all of these events, my privileged subjectivity in regard to gaming is something I have in common with most attendees. By dint of my identity as a straight white guy who games, I have been privy to utterances which participants might never say to more obviously-marked Others; I have been presumed a competent gamer and cultural insider, even when such competence is lacking; and I have been granted access to the intensely homosocial spaces of male-on-male gaming, where my bodily presence constitutes neither a threat nor an (overt or explicit) sexual distraction.

At the same time, my training in feminist ethnographic methods means I try to be aware of liminality, of bodies (including my own) and how they intermingle, wear down, and are prosthetically extendible and retractable, and of participants at the discursive and material margins of the contexts I attend. Traditions of feminist ethnography constitute both a methodological framework for conducting and conceptualizing my fieldwork, as well as grounds for understanding the cultural and epistemological politics - the regimes of power/knowledge - in play. I try to be aware of how participants read my (increasingly less youthful) body, and how my cis-male and heteronormative white identity, intersected with my investments in feminist research, frequently ensures that those participants who are most comfortable with my presence are the same ones whose actions and dispositions I am most interested in problematizing.

Accordingly, I have been afforded privileged insights into the logics, protocols, and affects associated with male-dominated play contexts. But, these epistemic affordances are all-too-readily subsumed back into hegemonic masculinity's project of sustaining gendered hierarchies and reproducing problematic traditions in social scientific research. In what follows, I explore some of these quandaries. These are by no means unique to studies of gaming; indeed, they reflect long-standing concerns of media ethnography, feminist social science, and critical masculinity studies. 
The first concerns localized exclusions. Here, I am interested in exploring some of the conditions through which game scholars who are straight, cis-male, and at or approaching middle age (which is to say, the "average gamer age," according to the Entertainment Software Association, 2017) can often contribute to the very patterns of exclusion and marginalization we may want to address and alleviate. By virtue of my ability to pass as a competent, confident male gamer, I have found myself in circumstances in which my actions and my bodily presence contribute to the marginalization and objectification of female participants.

The second quandary concerns one of the more problematic legacies of social science-science and/as subjugation. At times, in my work, I have treated research as a matter of processing participants, of guiding them through a protocol as efficiently as possible in order to then get on to the work of aggregating and analyzing their data. As tempting as this is, particularly under circumstances of pressure to produce scholarship, this stance invokes legacies of science as an extension of control, and of social science as a kind of resource extraction (Ezzy, 2010; Lather, 1986), both of which are historically tethered to patriarchal projects of domination (Smith, 2005), whether done in the service of ostensibly feminist research or not.

The third takes up an equally problematic tendency in hegemonic social science, which is to see without being seen. Inequitable politics of vision, whether enacted through long-standing methodological investments in objectivity or the more recent affordances of big data, help ensure that researchers remain unaccountable to their participants. These patterns of non-accountability are tied to legacies of violence, subjugation, and exploitation (Haraway, 1988; Tuhiwai Smith, 1999; Visweswaran, 1994).

\section{Walking the LAN}

The incident I consider here took place in the summer of 2011, at a large-scale LAN party in the south of England. This was my second time at this LAN series, held three times a year. I was present to gather data on massively multiplayer online game (MMOG) play at LANs - to solicit surveys, observe gameplay, conduct interviews, and invite participants to play an instrumented online game built specifically for the project.

The goal of this project, on which I was employed as a postdoctoral researcher, was to gain a robust, multi-faceted picture from as many participants as possible regarding how the MMOGs they played mediated their behaviors or, put differently (and in the ominous language of the broader government-funded program we were part of), to "infer real-life characteristics from in-game behaviors." As this phrase suggests, the research program imagined researchers would adopt an objective stance toward the processes of gamebased observation and data gathering: a gaze on gaming "from nowhere," as Haraway describes it (1988). Indeed, two of the five teams making up the program relied heavily on data recorded automatically by game servers, handed over to them by MMOG publish- 
ers. Our own team sought for a balance between a positivist, big data-driven approach, which the program managers saw as necessary in order to create reliable rules for inferring real-life characteristics, and the kinds of feminist, constructivist research in which I was trained during my graduate education. In other words, we sought to tack between the epistemologically and ethically distant poles of "god tricks" and "situated knowledges" (Haraway, 1988). Thankfully, our colleagues on the project, data scientists and analysts accustomed to working with interdisciplinary teams and trained in creative, rigorous applications of big data, supported us in this effort. They saw our insistence on face-toface interactions with participants as providing a kind of ground truth for the connections their quantitative wizardry could establish between participants' demographics and what they did and said in-game.

For my colleagues and I, trudging through the material terrains of this ground truth, the work was often logistically complex and emotionally draining. During my forays at large-scale LAN events, the multiplicity of data collection methods at our disposal, coupled with the imperative to recruit as many participants as we could and to ensure that the data was complete and that all facets (survey, interview, observations, and server logs of their instrumented game play) were properly labeled and sorted, meant that I often understood myself less as a researcher, and more as a mobile social science laboratory. Conventional ethnographic concerns around rapport-building were balanced with a desire to process participants as efficiently as possible: sign here, check here and here, navigate your browser tab to this URL, enter your unique user ID here, speak into this device, type into that one, etc.

At the particular LAN event I focus on here, I spent my first evening getting reacquainted with the layout and taking pictures of the main event floor where the administrative desks, promotional booths, and concession stands were located. I returned the following day in the early afternoon. The temporal rhythms of this LAN synchronized conveniently with my own jetlagged body; like me, most attendees did not rouse until late in the morning and crashed just before dawn. I had not yet settled into my process all humans state, and was content to browse the bottom floor of the event, where most of the MMOG play took place and, not incidentally, many of the older attendees closer to my age at the time (late 20s and above) were located. I soon spotted a group of attendees whom I had met on my trip to a LAN event the year before. They were part of a casual gaming clan, made up of white men and women in their late 20s and early 30 s who migrated together across several multiplayer games. The popular MMOG World of Warcraft (WoW) was their main gaming home at the time. As I had learned from my first interviews with them, they treated this regular LAN event as a chance to hang out for four days playing in close physical proximity together. Physical intimacy reflecting their social intimacy, their bodies extended into each other's LAN stations, and their gear (snacks, speakers, headphones, extra cables, etc.) intermingled into a continuous mass of stuff piled up behind their row of computers. 
I walked over to where the seven of them, all male, sat closely together, during a lull in their WoW group play. I was greeted warmly; some smiled or nodded from their seats, and others stood up to slap me on the shoulder or shake my hand. Two exclaimed, "Hey, it's the Canadian!" apparently in reference to the most notable thing about me from our last encounter. I explained that I had returned to continue the same research project as the first time we had met, this time with an instrumented game they could play together online which would automatically collect behavioral data, and they all acquiesced. Consent forms were distributed and signed, and I helped them log into the browser-based game. Built specifically for our research project, it invoked the look and feel of isometric role-playing games (RPGs) from the mid-90s, albeit without the narrative polish and loaded with a built-in surveillance apparatus.

Once they were all logged into the game, I wandered off to give them time alone to play. When I checked back 15 minutes later, I saw that most of them had progressed in the game (finished a number of quests, and advanced to experience level 5 , where the game afforded the chance to choose a specialization for their characters). At the same time, they had started to talk loudly and make fun of each other and the game, and a few had alt-tabbed out to go on internet relay chat (IRC), Steam, and various media players, exhibiting the kind of fluid, multi-layered communicative media practices characteristic of participants at large-scale LANs (Taylor \& Witkowski, 2010).

\section{Leaning Out}

Two of the gamers, in particular, were snickering over events in an IRC channel, and I walked over to ask them about it. They responded that the LAN had been visited by a group of promotional models who were circulating the floor, handing out swag for their tech company. As I watched, these two participants communicated via IRC with attendees on other floors, in an attempt to first have their confederates visually locate a promotional model and then to "send her over" to their area. They were both sheepish and determined in their aim, and, after another five minutes, a young woman arrived in uniform (pink nylon hot pants and a matching halter top, with a more modest fleece vest over the top), bearing candies emblazoned with her company's logo. Her arrival invoked a small amount of fanfare from the group, including high-fives between the two participants who had successfully lured her over via their IRC crowdsourcing. After some backand-forth with a couple group members, she agreed to pose for a photo, with the two IRC operators each holding items of some significance to the group as inside jokes-one held a pineapple with writing on it in front of his chest (I never learned what it said), while another hoisted a plush pig between himself and the model. I am in the frame, looking incredibly uncomfortable; I am not in physical contact with any of the participants, and I am leaning away from them in an effort to stand outside of the shot (Figure 1). 


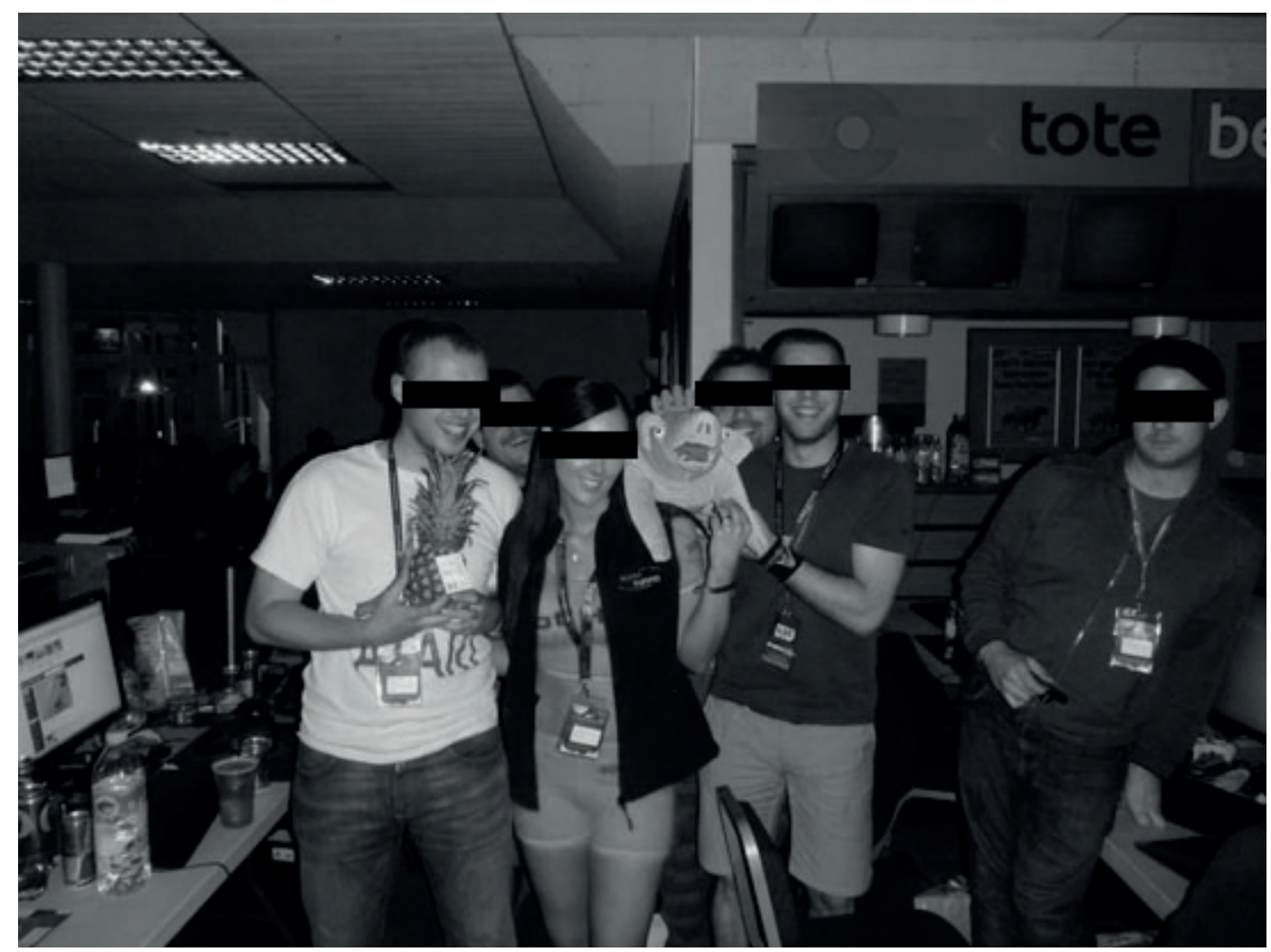

Figure 1. On the right, I lean out of an awkward situation. Photo owned by Nicholas Taylor.

\section{Discussion}

This anecdote illustrates some of the conditions of possibility, and the quandaries alluded to above, involved in "researching gamers while straight, white, male, and feminist." I turn to each of these quandaries, in turn, before reflecting on the methodological implications of the photograph itself, and its connections to the broader cultural politics of knowledge production in games and media studies.

\section{Good data?}

In this exchange, masculinity mediated an interaction between these male participants and I, marking me an insider culturally, if not interpersonally. This, coupled with my failure to do anything to disrupt this incident beyond my tepid reaction to it, arguably made me complicit in this objectification of the promotional model. Indeed, despite my discomfort, this exchange proved potentially beneficial to me; from the perspective of theoretical and methodological orientations to studies of gender and gameplay which have long been concerned with documenting, rather than intervening into gendered inequalities in 
digital game cultures, it constitutes good data. It serves as further evidence that female participation in many game events is often channeled into forms which serve the male gaze and, furthermore, affirm the compulsory heterosexuality of attendees.

On this point, however, it is useful to ask: Is this good data? For whom, and for what purposes? Do we need more reminders of the kind of entitlement male players take for granted, entitlement cultivated through a media apparatus in which they exercise a sense of entitlement over not just the games and the (offline and online) spaces of play, but over the activities of women in those contexts? We already have ample evidence of this (for one among many examples of excellent scholarship on this topic, see Consalvo, 2012). Do we need more proof? As Jenson and de Castell have pointed out (2008), gender and gaming scholars have proven adept at continually rediscovering girls' and women's marginalization in various aspects of gaming culture. What we need more of, they argue, are interventions into these conditions so as to report different, more affirming stories about equitable participation in gaming cultures.

I wonder, now, what I could have done differently. As I had experienced in previous fieldwork, and as other critical masculinities scholars have noted when studying men whose social and political capital is roughly equal to their own (Carrington, 2008; Robertson, 2006), my status as a researcher granted me no particular authority within these gaming communities, as it may have among comparatively less privileged participants. At the same time, I am curious about what would have happened had I been accompanied by a female colleague; whether these men would have felt so comfortable manipulating the activities of the promotional model had another woman been present. At the very least, I can see how my own ability to associate easily with these participants in this context provided cover for these men to make a pass at her. Straight white male game researchers like me arguably have the least fraught access to sites like LAN events, eSports tournaments, and arcades. Nonetheless, such access brings with it the question of when it is appropriate (if ever) to stay dialed in to certain masculine dispositions, to simply gather the data and move on-and when it is appropriate to challenge participants on their exploitive, objectifying, and/or marginalizing behaviors, at the risk of losing rapport with, and even access to, those communities.

\section{Instruments of domination}

Another related quandary here concerns the orientation to data collection I adopted at this event (and others like it), an orientation which meant I was perhaps less attuned to, and less capable of, navigating this particular exchange in a more productive manner. As mentioned, the goal of the research project which placed me in that LAN was to gather enough qualitative data of MMOG play in public settings (observations, field notes, interviews, photo diaries, etc.), so as to substantiate more generalized claims about what our online behavior says about our demographic backgrounds. Thinking about my agency in 
terms of a media instrument, combining my privileged subjectivity, ethnographic training, and investment in the project, I found myself primed toward a highly instrumental view of attendees: I viewed them as potential participants and sources of data, singling them out for approach beforehand, based on what I perceived to be their openness (Were they chatting with their neighbors?), as well as their potential added value to our study (Were they playing games for which we had not yet gathered data?). Once I had them signed up for the study, my aim was to get them through as efficiently as possible.

This general approach to data collection is certainly not confined to media studies, nor is it unique to one particular site or one particular method; it was foundational to the early nation-building projects of the social sciences, as a means of subjecting populations (both foreign and domestic) to measurement and categorization. This orientation to social science has only become intensified in the last few decades, via the emergence of pervasive surveillance apparatuses and the economic power garnered through farming, mining, and operationalizing personal data (Andrejevic, 2016).

That I would adopt this orientation in my own fieldwork, even in a small-scale wayconfiguring my body toward becoming a more efficient media instrument for collecting data on LAN attendees-illustrates two further forms of complicity afforded and amplified by my investments in masculinity. On one hand, my concern with processing participants demonstrates the allure, not to mention the common sense pervasiveness, of a discourse which equates sample size to the ability to make truth claims. This discourse has been fairly well-established in game studies, particularly given the incredible productivity and reach of scholars such as Yee and Williams, who base their prolific and highly cited scholarship on access to massive amounts of data gathered automatically on players' in-game behaviors, via the robust surveillance systems which undergird contemporary online games (Kerr, De Paoli, \& Keatinge, 2014; Whitson \& Simon, 2014). On the other, it points to the deep-seated historical connections between masculinity, as a project rooted in domination, and legacies of social science in which human subjects become simply inputs for a machine whose output is the scientific reproduction of difference (and inequality). It would be an understatement to say this orientation to social science contradicts the principles of feminist ethnography; it is, as I understand it, at the core of what feminist and indigenous ethnography has sought to disrupt (Smith, 2005; Tuhiwai Smith, 1999).

\section{A Malinowski moment?}

There is a further, equally pernicious set of histories at play in the production of this photograph. My attempt to lean out of the shot is, of course, an attempt to not be visible-to hide my presence and, by extension, my complicity in an exchange which I found awkward and problematic. It is my very own Malinowski Moment, in reference to the photograph accompanying Argonauts of the Western Pacific in which Bronislaw Malinowski sits 
in the shadowed cool of his tent, in the foreground, against a backdrop of natives gazing past him, their bodies and faces mostly visible (Figure 2). There are obviously numerous, important differences between my awkward photo and that of Malinowski in his tent. One is paradigmatic of a "golden age" of early anthropology; the other, taken 100 years later, depicts a promotional model posing with a bunch of dudes at a LAN party, one of whom looks conspicuously uncomfortable. But the similarities are worth noting: in both, the body of the researcher is held apart from his research participants. They are in their natural element; we are among them, but not of them, and we hold fast to that distinction, whether out of colonialist condescension (Baker, 1987), or out of discomfort with an objectionable moment.

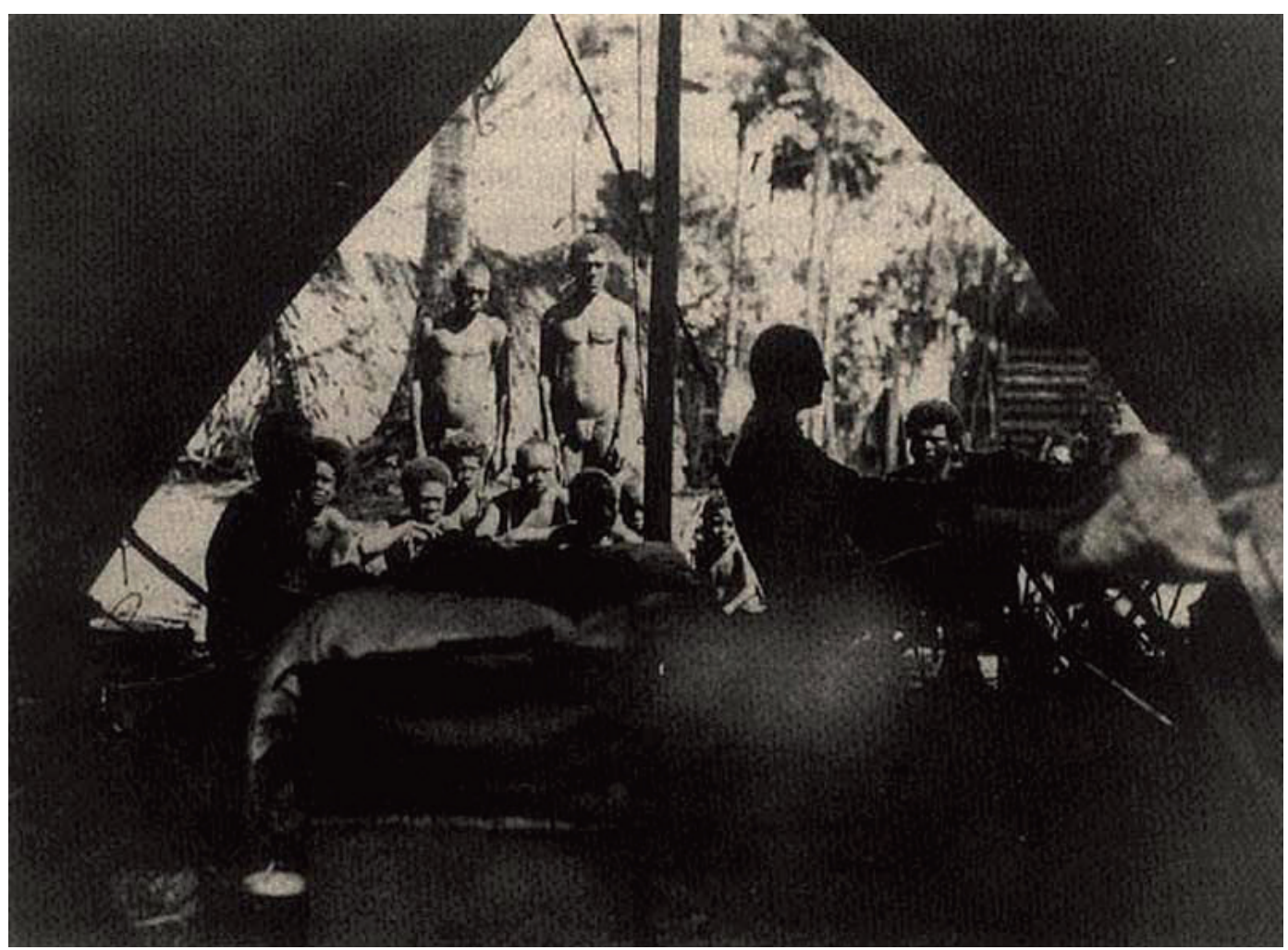

Figure 2. Bronislaw Malinowski pitches a tent. Photo by George Stocking, from History of Anthropology, Volume 1: Observers Observed: Essays on Ethnographic Fieldwork. Published in 1983 by the University of Wisconsin Press.

Again, this is an orientation to knowledge production which many feminist social scientists find deeply problematic, as to see without being seen, to place ourselves beyond the scrutiny and accountability of our participants enables us to act with disregard toward their safety and well-being (Haraway, 1988; Visweswaran, 1994). 
As with the greatly expanded and intensified capacity to record participants' behaviors, mentioned above, digital media have also given powerful new tools, and renewed vigor, to this centuries-old masculinist project of perfecting the "god trick" (Haraway, 1988). The social scientists studying online gaming mentioned above, for example, mine data on players' in-game behaviors, to which players themselves have not explicitly consented-that is, if we insist on the fundamental distinctions between an informed consent form and an end user license agreement (Chee, Taylor, \& de Castell, 2012). Indeed, Williams's consulting firm is called Ninja Metrics, glibly equating big data analytics with the capacity to inflict violence without detection. Underlying the novel technological conditions afforded to these data assassins is the same masculinist fantasy of the total, weaponized vision which Haraway describes:

\section{[...] the eyes have been used to signify a perverse capacity - honed to perfection in the history of science tied to militarism, capitalism, colonialism, and male supremacy - to distance the knowing subject from everybody and everything in the interests of unfettered power (Haraway, 1988, p. 581).}

My attempt to escape the frame (which in the moment, was simply a visceral reaction) can be contextualized within this broader history surrounding the politics of unequal vision in social science-an orientation that, in game studies, according to Suzanne de Castell et al. (2014), has generated research that often pathologizes certain play practices.

This discussion is not intended as a straightforward rejoinder for other straight, male researchers to check their privilege when it comes to studies of masculinized gaming communities and practices, though certainly more homework by scholars occupying positions of power would be a good thing (Visweswaran, 1994). I am more concerned with generating a better theoretical understanding of the foundational role our bodies and our intersectional locations play in the production of knowledge about gaming practices. I want to acknowledge that, while bodies like mine are well-positioned to access the more guarded spaces of gaming, such access can go hand-in-hand with investments in legacies of masculinity, science, and power which can transform acts of ethnographic negotiation and exploration into projects of domination and exploitation.

\section{Cyborg vs gamerbro?}

This represents, as mentioned, a provisional foray into a more rigorous accounting of the situated knowledges associated with male-identified researchers working in masculinized gaming contexts. The issues I raise are certainly not specific to game studies; researchers have been wrestling for years with questions of complicity, considerations around whether and how to disguise one's commitments to ideals that might run contrary to those of the study participants, and the ethical dilemmas involved in attempting critical and feminist ethnographies with privileged groups. At the same time, as I previously 
noted, these issues have not been broached by game scholars who have arguably gained the most from the associations between gaming and hegemonic masculinity-aka straight, predominantly white guys who game.

To better explain the stakes involved here, and to offer at least an abstract answer to these quandaries, I want to turn to the tension invoked in the title of this article, which deliberately (if somewhat nervously) alludes to Haraway's conclusion to her manifesto for cyborgs (1985). There, if I can at all pin Haraway's mischievous and protean writing to a singular reading, she seems to be turning toward the figure of the cyborg-in all its indeterminacy, defiance of binaries, and machinic entanglements - as a figure for feminist politics. Following the strident critique of feminism by women of color in the 1980s, Haraway seems to suggest that the figure of the cyborg provides a way forward for feminist science, rather than the goddess, with all its trappings of biologically-rooted agency and destiny. I want to (carefully) toy with the figure of the cyborg as it comes into contact with the media-theoretical understanding of masculinity which I offer here. That is, I want to depict the straight, male game researcher who is committed to feminism but tripped up by his own hybridity as a cyborg figure, as a way forward for a specifically feminist politics of studying gaming privilege while privileged. The foil here is far more antagonistic than in Haraway's comparison: it is not the goddess, but the gamerbro, the usually young, predominantly straight, often (though by no means exclusively) white, and almost always male subject who has long understood himself as the key player in gaming's cultural and economic ascendance, and who sees gaming as his natural domain.

The science of the gamerbro, as afforded by the myriad media instruments engineered through recently intensifying collaborations between behavioral scientists and game companies, is animated by a drive toward hierarchization, prediction, and control. It is a science of objectivism: the "unbiased" game review (Brathwaite, 2016), the "periscopic" study untainted by awareness of researcher presence (Taylor, 2008). It is also a science of machinic optimization: the pursuit of hyperefficiency via theorycrafting (Paul, 2011), the tekne of building a gaming rig (Simon, 2007). Within this apparatus, and as its key construct, the gamerbro is envisioned as agential and masterful. For him, games are the favored terrain in which he flexes the techno-muscular power and keen rationality which mark his synthesis of both jock and geek. He lives prosthetically, but denies any need for technological enhancement; his technologies are "extensions of man" (McLuhan, 1964), but without the interpenetration, since his body is inviolable.

Conversely, the cyborg in this theoretical simulation is both complicit and compromised. It is an entity potentially capable of accessing, exploring, and reporting on domains of digital media conventionally dominated by straight male gamers (the eSports tournament, the man cave, and the arcade), and able therefore-ideally — to problematize the very material-discursive conditions which make such domination persist. The cyborg's role, in this reckoning, is to sniff out the edges and fissures of the apparatus, and to work against their pre-programmed (but always culturally determined) inclinations toward the 
science of domination. This cyborg does so by employing a feminist orientation to relations, liminalities, and bodies in all their heterogeneous and dynamic entanglements.

As I have attempted to explain here, since this figure operates within and moves through the media apparatus of contemporary technomasculinity, which is at the same time its naturalized environment, some degree of vigilance is required. This cyborg needs to develop a sensitivity to the apparatus's pernicious formations of power/knowledge, and to the exploitative orientations toward research subjects which the apparatus readily provides. The central problem here, if we are to understand masculinity as mediating this exchange, is as old as critical analyses of media themselves: Can we hijack the channel without losing ourselves in it?

This is more than a rhetorical question, and, by way of conclusion, I offer three possibilities. If, as I have outlined here, ethnographers' bodies are media instruments capable of recording, processing, and communicating some forms of knowledge and not others-a media-theoretical take on Haraway's notion of "situated knowledges" (Haraway, 1988) then group ethnography is a potentially powerful means for generating ethnographic accounts which are richer, more robust, and multiply situated. In 2016, I had the opportunity to conduct fieldwork at a large-scale LAN in Europe with two female colleagues, both of whom are established feminist eSports scholars. While a fuller account of this fieldwork is beyond the scope of this article, that experience demonstrated to me (among many other lessons) the value of multiple points of access into and through the same field site, and the epistemological trajectories available to three researchers with very distinct histories, perspectives, and interests.

Feminist interventionist work provides another way around the quandaries I have outlined here. In addition to the pioneering research done to create and then document increases in girls' gaming competencies (and related social agency) in elementary school gaming clubs (Jenson, Fisher, \& de Castell, 2011), similar approaches have been instrumental in challenging the male-dominated status quo in independent game design (Fisher \& Harvey, 2013) and competitive gaming, most notably through the AnyKey.org initiative led by Morgan Romine and T.L. Taylor. These activities have the potential to circumvent concerns over how to conduct research on masculinized gaming cultures by inventing conditions for increased diversity, and then studying whether and how such conditions might be extended and sustained. Where collaborative ethnography provides a heterogeneity of media instruments, feminist interventions construct wholly new apparatuses, however temporary.

Finally, given the politics of knowledge production associated with the gamerbroobjectivist, oriented toward prediction and control, and driven by the economic imperatives of the game industry-one additional strategy for confronting masculinist legacies of social science in digital game studies may be to cultivate (and agitate for) more mindful citational practices. Feminist scholars have noted a tendency across a number of disciplines to cite what has already been cited. This often leads to over-citations of 
a white, heterosexual, and Eurocentric canon, even in disciplines ostensibly invested in supporting a diverse range of voices and backgrounds (Blackman, 2015; Mott \& Cockayne, 2017), and especially in instances where females, people of color, and/or queer scholars did the work first (Ahmed, 2014). In 2015, Gray noted this tendency with regard to digital game studies. She launched the \#citeherwork hashtag campaign as a response to what she saw as a politics of erasure, noting "the constant struggle of women in academia having their work acknowledged as valid contributions to the literature and field" (n.p.). In addition to pursuing collaboration with researchers from different backgrounds, and aiding projects which contribute in direct ways to the advancement of underrepresented groups in media and technology, we might therefore include \#citeherwork as a further strategy for the technomasculine-feminist cyborg. This is particularly fitting when we understand that citational practices, much like social scientific methods, are not simply ancillary to the (de)construction of hegemony in academia; as Ahmed (2014) notes, they are the bricks that build the walls which have historically kept others out.

\section{References}

Abu-Lughod, L. (1997). The interpretation of culture(s) after television. Representations, 59, 109-134.

Ahmed, S. (2014). White men. Feministkilljoys. Retrieved from: https:/feministkilljoys.com/2014/11/04/ white-men/

Andrejevic, M. (2016). Theorizing drones and droning theory. In A. Završnik (Ed.), Drones and unmanned aerial systems: Legal and social implications for security and surveillance (pp. 21-43). Switzerland: Springer.

Baker, V. (1987). Pitching a tent in the native village: Malinowski and participant observation. Journal of the Humanities and Social Sciences of Southeast Asia, 143(1), 14-24.

Banet-Weiser, S., \& Miltner, K.M. (2016). \#MasculinitySoFragile culture, structure, and networked misogyny, Feminist Media Studies, 16(1), 171-174.

Behrenshausen, B.G. (2007). Toward a (kin)aesthetic of video gaming: The case of dance dance revolution. Games and Culture, 2(4), 335354.

Blackman, L. (2016). Social media and the politics of small data: Post publication peer review and academic value. Theory, Culture \& Society, 33(4), 3-26.

Brathwaite, A. (2016). It's about ethics in games journalism? Gamergaters and geek masculinity. Social Media + Society. DOI: 10.1177/2056305116672484

Burrell, J. (2009). The field site as a network: A strategy for locating ethnographic research. Field Methods, 21, 181-199. DOI: 10.1177/1525822X08329699

Carrington, B. (2008). "What's the footballer doing here?": Racialized performativity, reflexivity, and identity. Cultural Studies $\leftrightarrow$ Critical Methodologies, 8(4), 423-452.

Chee, F.M., Taylor, N.T., \& de Castell, S. (2012). Re-mediating research ethics: End-user license agreements in online games. Bulletin of Science, Technology \& Society, 32(6), 497-506.

Chess, S. (2017). Ready player two: Women gamers and designed identity. Minneapolis: University of Minnesota Press. 
Chess, S., \& Shaw, A. (2015). A conspiracy of fishes, or, how we learned to stop worrying about \#gamergate and embrace hegemonic masculinity. Journal of Broadcasting \& Electronic Media, 59(1), 208-220.

Connell, R.W. (2014). The study of masculinities. Qualitative Research Journal, 14(1), 5-15.

Consalvo, M. (2012). Confronting toxic gamer culture: A challenge for feminist game studies scholars. Ada: A Journal of Gender, New Media, and Technology, 1. DOI: 10.7264/ N33X84KH

Cross, K. (2017). How Trump Is trying to govern America like an internet troll. Rolling Stone. Retrieved from: http://www.rollingstone.com/politics/features/how-trump-is-trying-to-govern-america-like-aninternet-troll-w468518

Davies, C.A. (1998). Reflexive ethnography: A guide to researching ourselves and others. New York: Routledge.

De Castell, S., Jenson, J., Taylor, N., et al. (2014). Re-thinking foundations: Theoretical and methodological challenges (and opportunities) in virtual worlds research. Journal of Gaming and Virtual Worlds, 6(1), 3-20.

Entertainment Software Association. (2017). Industry facts. Retrieved from: http://www.theesa.com/ about-esa/industry-facts/

Ezzy, D. (2010). Qualitative interviewing as an embodied emotional performance. Qualitative Inquiry 16(3), 163-170.

Fisher, S., \& Harvey, A. (2013). Intervention for inclusivity: Gender politics and indie game development. Loading, 7(11). Retrieved from: http://journals.sfu.ca/loading/index.php/loading/article/view/118

Giddings, S., \& Kennedy, H. (2008). Little Jesuses and *@\#?-off robots: On cybernetics, aesthetics, and not being very good at Lego Star Wars. In M. Swalwell, \& J. Wilson (Eds.), The pleasures of computer gaming: Essays on cultural history, theory and aesthetics (pp. 13-32). Jefferson: McFarland.

Ging, D. (2017). Alphas, betas, and incels: Theorizing the masculinities of the manosphere. Men and Masculinities. DOI: 1097184X17706401

Gray, K.L. (2012). Intersecting oppressions and online communities. Information, Communication \& Society, $15,411-428$.

Gray, K.L. (2015). \#Citeherwork: Marginalizing women in academic and journalistic writing. Retrieved from: https://lachezbippy.kinja.com/citeherwork-marginalizing-women-in-academic-and-journ-1748501738

Haraway, D. (1985). Manifesto for cyborgs: Science, technology, and socialist feminism in the 1980s. Socialist Review, 80, 65-108.

Haraway, D. (1988). Situated knowledges: The science question in feminism and the privilege of partial perspective. Feminist Studies 14(3), 575-599.

Harper, T. (2014). The culture of digital fighting games: Performance and practice. New York: Routledge.

Harrison, B., \& Roberts, D.L. (2011). Using sequential observations to model and predict player behavior. Paper presented at the Foundations of Digital Games conference, Bordeaux, France, 29 June-1 July 2011.

Hine, C. (2015). Ethnography for the Internet: Embedded, embodied and everyday. New York: Bloomsbury Publishing.

Hsu, J. (Jan. 2015). Inside the largest virtual psychology lab in the world. Medium. Retrieved from: https:// medium.com/backchannel/inside-the-largest-virtual-psychology-lab-in-the-world-7c0d2c43cda5

Jenson, J., \& de Castell, S. (2008). Theorizing gender and digital gameplay: Oversights, accidents and surprises. Eludamos. Journal for Computer Game Culture, 2(1), 1525.

Jenson, J., Fisher, S., \& de Castell, S. (2011). Disrupting the gender order: Leveling up and claiming space in an after-school video game club. International Journal of Gender, Science and Technology, 3(1), 148-169.

Johnson, R. (2010). The digital Illusio: Gender, work and culture in digital game production. Ph.D. thesis, University of lowa. Retrieved from: http://ir.uiowa.edu/etd/524 
Johnson, R. (Forthcoming). Technomasculinity and its influence in video game production. In N. Taylor, \& G. Voorhees (Eds.), Masculinity and gaming: Mediated masculinities in play. New York: Palgrave Macmillan.

Kerr, A., De Paoli, S., \&, Keatinge, M. Surveillant assemblages of governance in massively multiplayer online games: A comparative analysis. Surveillance and Society, 12(3), 320-336.

Kocurek, C. (2015). Coin-operated Americans: Rebooting boyhood at the video game arcade. Minneapolis: University of Minnesota Press.

Lather, P. (1986). Research as praxis. Harvard Educational Review, 56(3), 257-277.

Mankekar, P. (1999). Screening culture, viewing politics: An ethnography of television, womanhood and nation in postcolonial India. Durham: Duke University Press.

Massanari, A. (2017). \#Gamergate and The Fappening: How Reddit's algorithm, governance, and culture support toxic technocultures. New Media and Society, 19(3), 329-46.

Mayer, V. (2001). When the camera won't focus: Tensions in media ethnography. Feminist Media Studies, 1(3), 307-322.

Mayer, V. (2006). Research beyond the pale: Whiteness in audience studies and media ethnography. Communication Theory, 15(2), 148-167.

McLuhan, M. (1964). Understanding media: The extensions of man. New York, NY: McGraw-Hill.

Messner, M.A. (2016). Forks in the road of men's gender politics: Men's rights vs feminist allies. International Journal for Crime, Justice and Social Democracy, 5(2), 6-20.

Mott, C., \& Cockayne, D. (2017). Citation matters: Mobilizing the politics of citation toward a practice of "conscientious engagement." Gender, Place and Culture, 24(7), 954-973.

Murphy, P.D. (2008). Writing media culture: Representation and experience in media ethnography. Communication, Culture \& Critique, 1(3), 268-286.

Niedenthal, S. (2012). Skin games: Fragrant play, scented media and the stench of digital games. Eludamos. Journal for Computer Game Culture, 6(1), 101131.

Ortiz, S.M. (2005). The ethnographic process of gender management: Doing the "right" masculinity with wives of professional athletes. Qualitative Inquiry, 11(2), 265-290.

Packer, J. (2013). The conditions of media's possibility: A Foucauldian approach to media history. In J. Nerone (Ed.), Media history and the foundations of media studies (pp. 1-34). New York: Blackwell.

Packer, J., \& Wiley, S.B.C. (2012). Introduction: The materiality of communication. In J. Packer, \& S.B.C. Wiley (Eds.), Communication matters: Materialist approaches to media, mobility, and networks (pp. 3-16). New York: Routledge.

Paul, C.A. (2011). Optimizing play: How theorycraft changes gameplay and design. Game Studies, 11(2). Retrieved from: http://gamestudies.org/1102/articles/paul

Paul, C.A. (2018). The toxic meritocracy of video games: Why gaming culture is the worst. Minneapolis: University of Minnesota Press.

Pertierra, A., \& Turner, G. (2013). Locating television: Zones of consumption. New York: Routledge.

Peters, J.D.P. (2015). The marvelous clouds: Toward a philosophy of elemental media. Chicago: University of Chicago Press.

Phillips, W. (2015). This is why we can't have nice things: Mapping the relationship between online trolling and mainstream culture. Cambridge, MA: MIT Press.

Pink, S. (2009). Doing sensory ethnography. London: SAGE.

Ratan, R., Taylor, N., Hogan, J., et al. (2015). Stand by your man: An examination of gender disparity in League of Legends. Games and Culture, 10(5), 438-462.

Robertson, S. (2006). Masculinity and reflexivity in health research with men. Auto/biography, 14(4), 302319. 
Seiter, E. (1990). Making distinctions in TV audience research: Case study of a troubling interview. Cultural Studies, 4(1), 61-84.

Shaw, A. (2015). Gaming at the edge: Sexuality and gender at the margins of game culture. Minneapolis: University of Minnesota Press.

Simon, B. (2007). Geek chic: Machine aesthetics, digital gaming, and the cultural politics of the case mod. Games and Culture, 2(3), 175-93.

Smith, D.E. (2005). Institutional ethnography: A sociology for people. Toronto: Altamira Press.

Sundén, J. (2009). Play as transgression: An ethnographic approach to queer game cultures. Proceedings of DiGRA 09: Breaking New Ground: Innovation in Games, Play, Practice and Theory. Retrieved from: http://www.digra.org/dl/db/09287.40551.pdf

Taylor, N. (2008). Periscopic play: Re-positioning "the field" in MMO Studies. Loading, 2(3). Retrieved from: http://journals.sfu.ca/loading/index.php/loading/article/view/43

Taylor, N. (2016). Play to the camera: Video ethnography, spectatorship, and e-sports. Convergence, 22(2), 115-130.

Taylor, N., Jenson, J. \& de Castell, S. (2009). Cheerleaders/booth babes/Halo hoes: Pro-gaming, gender and jobs for the boys. Digital Creativity, 20(4), 239-252.

Taylor, N., \& Voorhees, G. (forthcoming). The empire's new bros: Gaming, masculinity, power. In N. Taylor, \& G. Voorhees (Eds.), Masculinity and gaming: Mediated masculinities in Play. New York: Palgrave Macmillan.

Taylor, T.L. (2012). Raising the stakes: E-sports and the professionalization of computer gaming. Cambridge, MA: MIT Press.

Taylor, T.L., \& Witkowski, E. (2010). This is how we play it: What a mega-LAN can teach us about games. Paper presented at the Foundation of Digital Games conference, Monterey, CA, 19-21 June 2010.

Thomas, L. (1995). Feminist researchers and "real women": The practice of feminist audience research. Changing English, 2(2), 113-29.

Tuhiwai Smith, L. (1999). Decolonizing methodologies: Research and indigenous peoples. New York: Zed Books.

Visweswaran, K. (1994). Fictions of feminist ethnography. Minneapolis: University of Minnesota Press. Voorhees, G. (2015). Neoliberal masculinity: The government of play and masculinity in e-sports. In T. Oates \& R. Bookey (Eds.), Playing to win: Sports, video games, and the culture of play (pp. 63-91). Bloomington: Indiana University Press.

Whitson, J.R., \& Simon, B. (2014). Game studies meets surveillance studies at the edge of digital culture: An introduction to the special issue on surveillance, games and play. Surveillance and Society, 12(3), 309-319.

Witkowski, E. (2013). Eventful masculinities: Negotiations of hegemonic sporting masculinities at LANs. In M. Consalvo, K. Mitgutsch, \& A. Stein (Eds.), Sports videogames (pp. 217-235). New York: Routledge.

Nicholas Taylor, PhD. Assistant Professor

Department of Communication Associate Director of the PhD Program in Communication, Rhetoric and Digital Media (CRDM) North Carolina State University nttaylor@ncsu.edu 